\title{
DEVELOPMENT OF NEW NITRIDED NICKEL-BASE ALLOYS FOR HIGH TEMPERATURE APPLICATIONS
}

\author{
Claudio D. Penna \\ Institute of Metallurgy \\ Swiss Federal Institute of Technology - Zentrum \\ 8092 Zurich - Switzerland
}

\begin{abstract}
The development strategy for what we believe to be a highly promising new family of superalloys is presented. Most superalloys reach their upper limit for useful service above $900^{\circ} \mathrm{C}$ : age hardened alloys encounter a dramatic drop of their very high strength because precipitates are no longer thermally and/or thermodynamically stable. Solid solution alloys still provide useful strengths slightly above $1000^{\circ} \mathrm{C}$. In the temperature range 800 to $1100^{\circ} \mathrm{C}$ other strengthening mechanisms and phases must be used: examples are ODS alloys. The development presented consists in the production of a fairly fine grain structure $(\sim 50 \mu \mathrm{m})$ in which nitride particles (with a size of 1-5 $\mu \mathrm{m}$ ) are dispersed in order to avoid grain growth at high temperatures, and in the use of solid solution additions to promote additional high temperature strength and creep resistance. The useful temperature of this new alloy is situated in a range above $800^{\circ}$, up to $1100^{\circ} \mathrm{C}$; below $800^{\circ} \mathrm{C}$ age hardened alloys are much stronger and therefore more suitable.

The alloys were produced by nitriding a $\mathrm{Ni}-\mathrm{Cr}$ melt under high nitrogen partial pressure. For typical content of $0.5-0.8 \mathrm{~N}$ during alloy solidification 10-20vol.\% nitrides were formed, and homogeneously dispersed in the matrix after thermomechanical treatment. A grain size close to $50 \mu \mathrm{m}$ was obtained. The nitridation and themomechanical treatments have been carried out for different alloy compositions with a common $\mathrm{Ni}-\mathrm{Cr}-\mathrm{N}$-base. The microstructure was shown to have a fairly good stability at $1100^{\circ} \mathrm{C}$.

Small grains are believed to be deleterious for creep resistance, because they can lead to accelerated creep by grain boundary sliding: for this reason many high temperature alloys do not contain grain boundaries or only very low angle ones and some others (ODS or DS) have large elongated grains. However, good creep resistance is believed to be achievable by stabilizing grain boundaries by the nitrides.

In the alloys at temperatures below $1120^{\circ} \mathrm{C}$ the $\pi$ nitride was ob-
\end{abstract}

served; its precipitation was accompanied by a volume variation, which was measured by dilatometry. W, Mo and Ta were considerated as possible solid solution strengtheners and their effect tested on the alloys. W was identified as best candidate. The $\pi$ nitride was found to be greatly stabilized by additions of Mo and W.

High temperature tensile tests revealed that the presence of nitrogen and tungsten induces a remarkable strengthening as well as the appearance of a pronounced yield phenomenon in the stress-strain behavior. Strength levels above $150 \mathrm{MPa}$ at $1000^{\circ} \mathrm{C}$ were reached already with nitride-free $\mathrm{Ni}-\mathrm{Cr}-\mathrm{N}-\mathrm{W}$ alloys. 


\section{Introduction}

A fundamental way of reaching higher efficiencies in a gas turbine is to raise the service temperaturc. As a consequence, there is a constant demand, from strength and corrosion points of view, for materials suitable for ever higher service temperatures. Motivated by this challenge we are developing a concept to obtain elevated temperature strength in nickel-base alloys.

When considering the use of alloys at high homologous temperatures $(\mathrm{T} / \mathrm{Tm}>0.5)$ thermally activated processes start to play an important role; new glide systems may become active and diffusion causes microstructure evolutions, additionally vacancy diffusion assisted creep, dislocation climb as well as grain boundary migration and grain boundary sliding can occur.

Superalloys found today in high temperature applications, such as gas turbines, are based mainly on $\gamma^{6}$ precipitation strengthening, solid solution hardening or particles dispersion strengthening (or a combination of these). If specific mechanical properties at service temperatures above $900^{\circ} \mathrm{C}$ are required, precipitation strengthening might no longer be suitable because precipitates become unstable or rapidly coarse due to coalescence. Most superalloys reach therefore their upper limit for useful service above $900^{\circ} \mathrm{C}$ : age hardened alloys such as Nimonic 80A or Waspaloy encounter a dramatic drop of their very high strength. Solid solution alloys such as Hastelloy $\mathrm{W}$ or Haynes 230 still provide useful strengths slightly above $1000^{\circ} \mathrm{C}$. In the temperature range 800 to $1100^{\circ} \mathrm{C}$ other strengthening mechanisms and phases musl be used: examples are ODS alloys. Oxides dispersion (ODS) alloys provide reliable strength up $1100^{\circ} \mathrm{C}$; however, their anisotropy, limited workability, relatively expensive cost and small rupture strain restrict their application. Superalloys development for service temperatures above $900^{\circ} \mathrm{C}$, up to $1100^{\circ} \mathrm{C}$, in the last decade has been characterized by strong solid solution strengthening additions together with the appearance of relatively fine-grained microstructures. A nickel matrix containing between 20 and 30 percent chrome is a common feature of these alloys (Iaynes alloy HR120 and HR230, Inco Alloy 601GC and others $[1,2,3])$ taking advantage of the high temperature stability of the cfc- $\gamma$ phase and the high chromium content to increase the resistance to oxidation.

The development strategy for what we believe to be a highly promising new group of Ni-base superalloys is based on strengthening a $\mathrm{Ni}-\mathrm{Cr}$ matrix with nitrogen and some substitutional solid solution strengtheners on one side; and by creating a fine grain microstructure stabilized against grain growth by the precipitation of nitrides, on the other side.

\section{Solid solution strengthening}

At high temperature solid solution strengthening is mainly due to elastic (misfit) and modulus interactions between matrix and foreign atoms, while other contributions can be ignored [4]; interstitials usually have a stronger strengthening effect than substituted atoms (relative per unit concentration), due to the tendency to produce non-spherical distortion in the lattice.

In Table I a few elements, typically found in superalloys, are listed together with their atom radii and elastic properties. In a $\mathrm{Ni}-30 \mathrm{Cr}$ matrix best candidates based on differences in size and moduli are primarily Re, W and also Nb, Mo and Ta, as also found in ref. [2-5] Each increment of $10 \mathrm{wt} . \%$ of tungsten and molybdenum the creep rate decreases by an order of magnitude, where tungsten strengthens to a somewhat larger extent than does molybdenum [3], which is probably due to the difference in their elastic properties. Re as been also studied extensively as solid solution strengthener in nickel base alloys; it is also found to dramatically slow down diffusion at high temperatures [6]. Ta and $\mathrm{Nb}$ are often alloyed in order to precipitate intermetallic precipitates, as in Inconel 718.

Table I Relevant properties* of some elements for solid solution strengthening.

\begin{tabular}{cccc}
\hline & $\begin{array}{c}\text { Atomic radius } \\
{[\AA]}\end{array}$ & $\begin{array}{c}\text { Youngs modulus } \\
{[\mathrm{GPa}]}\end{array}$ & $\begin{array}{c}\text { Shear modulus } \\
{[\mathrm{GPa}]}\end{array}$ \\
\hline $\mathrm{Ni}$ & 1.62 & 207 & 76 \\
$\mathrm{~N}$ & 0.75 & - & - \\
$\mathrm{Co}$ & 1.67 & 211 & 83 \\
$\mathrm{Fe}$ & 1.72 & 200 & 81 \\
$\mathrm{Al}$ & 1.82 & 68 & 25 \\
$\mathrm{Cr}$ & 1.85 & 279 & 115 \\
$\mathrm{Re}$ & 1.97 & 469 & 176 \\
$\mathrm{Mo}$ & 2.01 & 330 & 120 \\
$\mathrm{~W}$ & 2.02 & 400 & 175 \\
$\mathrm{Ta}$ & 2.09 & 185 & 69 \\
$\mathrm{Nb}$ & 2.09 & 103 & 37 \\
\hline
\end{tabular}

* Data from: Metals Handbook, Vol.2, 10th ed., ASM Int. 1990

The strengthening by interstitial nitrogen in steel is remarkable at room temperature [7], and a similar effect should be expected in nickel based alloys.

If these elements are to be used as solid solution strengtheners then it also important to consider the relative stability of their nitrides. For instance $\mathrm{Ta}$ and $\mathrm{Nb}$ form very stable nitrides. While $\mathrm{Mo}$ and $\mathrm{W}$ form stable carbides, they are not very strong nitride formers [8]. In the case of $\mathrm{Ta}$, for instance, in a $\mathrm{Ni} 30 \mathrm{Cr}$ alloy containing nitrogen the matrix will be depleted of this element because of the precipitation of nitrides.

\section{Grain boundary strengthening}

For high temperature applications of polycristalline alloys, grain boundary sliding (GBS) has been identified as a major deformation mechanism $[9,10,11]$. In the creep deformation mechanism maps for pure nickel [12] large portions of the map are dominated by GBS. Because of their sliding at high temperature, grain boundaries have been avoided, partially or completely, by production of single crystals or directionally solidified alloys. In polycristal alloys a dispersion of sufficiently stable particles have been shown, theoretically and experimentally, to significantly reduce grain boundary sliding. In $\mathrm{Ni}$-base superalloys, grain boundary carbides have been shown to decrease the creep rate by suppressing GBS [9, 1013$]$. Of course avoiding grain boundaries, or using a coarse grains structure, will exclude grain boundary strengthening. It is not clear whether grain boundary strengthening can be effective at temperatures above $900^{\circ} \mathrm{C}$, although it has been shown that the Petch slope $\mathrm{k}_{\mathrm{y}}$ varies weakly in the 77 to $300^{\circ} \mathrm{K}$ temperature range for a series of binary $\mathrm{Cu}-\mathrm{Ni}, \mathrm{Cu}-\mathrm{Zn}$ and $\mathrm{Cu}-\mathrm{Al}$ alloys [14]. Grain boundary strengthening is known to be very effective in ferritic steels, but less so in austenitic iron based alloys [15].

\section{Grain growth}

In a similar way as with grain boundary sliding, particles are able to impede grain coarsening under certain conditions [16]. According to Ashby [17], at high homologous temperatures, for particles 
smaller than $r_{0}=3 / 2$ f $y / P$ (where $\gamma$ : boundary energy, $P$ : driving pressure, $\mathrm{f}$ : volume fraction of particles), the boundary mobility decreases with increasing particle size. At homologous temperatures of 0.8 the mobility is in most cases controlled by matrix or interface diffusion. However, for particles larger than $\mathrm{r}_{0}$ the boundary can escape and its intrinsic mobility is the controlling factor; in this range the model predicts an increasing mobility with increasing particle radius, calculated to be roughly of two orders of magnitude larger than for radii smaller than $r_{0}$. The lowest mobility should be obtained with a radius slightly smaller than $r_{0}$.

\section{The $\mathrm{Ni}-\mathrm{Cr}-\mathrm{N}$ system}

The solubility of nitrogen in iron-base melts is substantially higher than in a similar nickel-base alloys. The nitrogen solubility in a nickel-base melt can be raised by using higher partial pressures and alloying with $\mathrm{Cr}$. With nitrogen partial pressure up to $50 \mathrm{bar}$, one can put morc than $1 \% \mathrm{~N}$ in solution in the melt. The nitrogen solubility in the solid state for the same system is not as high, and primary nitrides precipitate. In this system four phases can be found depending on the temperature and composition: $\gamma$ (fcc matrix), an hexagonal chrome nitride $\mathrm{Cr}_{2} \mathrm{~N}(\varepsilon)$, a cubic chrome nitride $\mathrm{CrN}$ and a mixed nitride: the $\pi$ phase $[2,18,19]$. It has been concluded that the $\pi$ phase has the structure of $\beta$-manganese, and a stoichiometry close to $\mathrm{Cr}_{13} \mathrm{Ni}_{7} \mathrm{~N}_{4}$ [18]. At $1000^{\circ} \mathrm{C}$ the $\pi$ phase is formed through the peritectoid reaction:

$$
\gamma+\mathrm{Cr}_{2} \mathrm{~N} \rightarrow \pi
$$

The phase was found to be unstable above $1100^{\circ} \mathrm{C}$.

We have calculated the pseudo-binary phase diagram of the system $\mathrm{Ni}-\mathrm{Cr}-\mathrm{N}$, for $\mathrm{Cr}$ content varying from 20 to 30 percent (using the software program Thermocalc $\left.{ }^{\mathbb{B}}\right)$. In Figure 1 the pseudo binary phase diagram for $\mathrm{Ni} 30 \mathrm{Cr}$ alloyed with nitrogen is presented. It shows the temperature and composition range for the $\pi$ phase and of the $\varepsilon$ nitride. The calculation correlates fairly well with information found in the literature. Lowering the chromium content results in the appearance of the cubic nitride, ,coming from the right" in the diagram, and shifting to lower nitrogen concentration as the $\mathrm{Cr}$ content decreases further. Also the stability of the $\pi$ phase is decreased with lower chromium concentrations.

With the same program the influence of $\mathrm{Mo}, \mathrm{Ta}, \mathrm{Co}$ and $\mathrm{W}$ on the

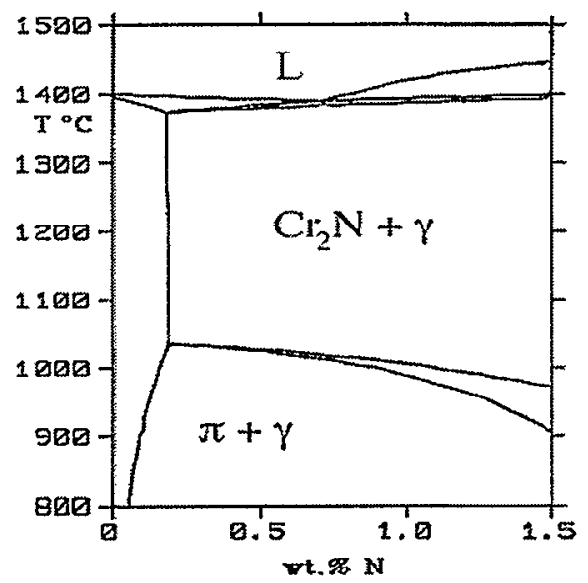

Figure 1: Ni30Cr-N pseudo binary equilibrium phase diagram calculated with Thcrmocalc®. pseudo-binary phase diagram of $\mathrm{Ni} 30 \mathrm{Cr}-\mathrm{N}$ can be tested. The calculations show that $\mathrm{Co}$, Mo and $\mathrm{W}$ have extended solubilities in $\gamma$. Cobalt was considered as a candidate for partial substitution of nickel to control alloy nitrogen solubility without influencing other properties. The thermodynamical calculation for tantalum predicts no solubility in $\gamma$ and the precipitation of an intermetallic $N$-free Ta$\mathrm{Ni}-\mathrm{Cr}$ phase and the $\pi$ nitride. Because of the stability of TaN [7] this prediction appears suspicious. In the case of tungsten, cobalt and molybdenum, the calculation shows that the $\pi$-phase can contain some W, Co and Mo respectively, by substitution of part of the Cr. The solubility limit of W in Ni20wt.\%Cr is $17.5 w t . \%$ [2].

\section{Alloy development strategy}

The system $\mathrm{Ni}-30 \mathrm{Cr}$ shows very interesting features for high temperature applications. The presence of chromium allows the precipitation of nitrides; which, according to the calculated phase diagram for nitrogen concentration lowcr than $\sim 0.7 \mathrm{wt} \%$, are not stable in the melt. It is therefore possible to precipitate a nitride in the $\gamma$ phase during the solidification of the alloy. If precipitation occurs in the melt, then some of the nitrides would be segregated either to the top or to the bottom of the melt. In the case of $\mathrm{CrN}$ and $\mathrm{Cr}_{2} \mathrm{~N}$, for instance, having densities of 6.1 and $6.5 \mathrm{~g} / \mathrm{cm}^{3}$ respectively, the precipitates would segregate in the slag (nickel base superalloys have densities of $8-10 \mathrm{~g} / \mathrm{cm}^{3}$ ). A high chromium content also provides good high temperature oxidation resistance, which can be further improved with small additions of $\mathrm{Y}[20]$.

Interesting mechanical properties have been recognized to the Ni$20 \mathrm{Cr}$ alloys strengthened with $\mathrm{W}$ and $\mathrm{Mo}[2,3]$ for high temperature applications. For instance Haynes ${ }^{1230}$ provides a $0.2 \%$ yield strength of $145 \mathrm{MPa}$ at $982^{\circ}$; this alloys contains $14 \mathrm{wt} . \% \mathrm{~W}$ and 2 wt.\% Mo. Good strength and creep resistance have also been obtained with the alloy $\mathrm{Ni} 30 \mathrm{Cr}(0.6-1) \mathrm{N}$ [19]; the 0.2 yield strength at $1000^{\circ} \mathrm{C}$ was $85 \mathrm{MPa}$, together with a 10,000 hours creep rupture strength higher than $12 \mathrm{MPa}$.

The development strategy for what we believe to be a highly promising new group of Ni-base superalloys is based on strengthening a $\mathrm{Ni}$ matrix with 20 to $30 \% \mathrm{Cr}$ with nitrogen and some substitutional solid solution strengtheners such as W, Mo and Ta on one side; and by creating a fine grain microstructure stabilized against grain growth by the precipitation of nitrides, on the other side. From a manufacturing point of view, this alloy can be produced by nitriding the melt, avoiding processing by powder metallurgy.

The development of this material demands fundamental investigations on several aspects: the phases that can occur as well as their properties, the role of interstitial nitrogen, the importance of its solid solution strengthening and grain boundary strengthening at high temperatures, the stability of the nitrides, the stability of the microstructure as well as the corrosion behavior. This paper presents the first part of the development dealing with the investigation on the Ni-Cr-N system and the influence of W, Mo and Ta as well as on the role of interstitial nitrogen on mechanical properties.

\section{Experimental procedure}

\section{Alloy manufacturing}

Alloys used in this work were produced in a vacuum induction furnace using pure $\mathrm{Ni}(99.95 \%), \mathrm{Co}(99.9 \%), \mathrm{Cr}(99.91 \%)$ and binary alloys of $55.2 \% \mathrm{Ni}-44.7 \% \mathrm{~W}, 56.2 \% \mathrm{Ni}-43.6 \% \mathrm{Ta}$ and $55.4 \% \mathrm{Ni}-$ $44.1 \% \mathrm{Mo}$ (compositions in wt.\%). 


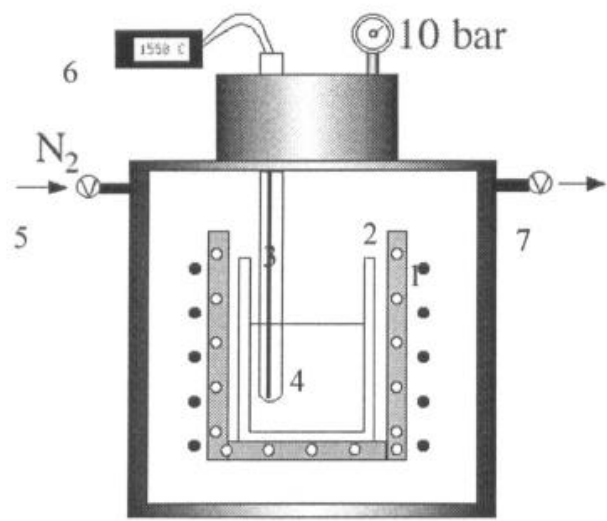

Figure 2: Schematic representation of the nitriding furnace. 1) Induction heating. 2) External crucible with cooling system. 3) Thermocouple. 4) Melt. 5) Nitrogen entry-valve. 6) Temperature indicator. 7) Exit valve. In order to evacuate the air prior to nitridation, the chamber is rinsed twice with at least 20 bar of nitrogen.

The $\mathrm{N}$-free alloys were then remelted in our in-house developed high nitrogen pressure induction furnace (see Figure 2). The applied nitrogen pressure can be set between 1 and 200 bar, depending on alloy composition and the amount of nitrogen needed. The nitriding time and temperature were always 60 minutes and $1550^{\circ} \mathrm{C}$, respectively. Typical pressures for $\mathrm{Ni} 30 \mathrm{Cr}$-based alloys in order to obtain $0.5-0.8 w t . \%$ nitrogen are $15-25$ bar. This values vary quite strongly with the $\mathrm{Cr}$-content, as well as with the nature of other alloying elements. Once a 60 minutes nitriding time is reached, the melt is rapidly cooled down $\left(\sim 67^{\circ} \mathrm{C} / \mathrm{min}\right.$.) by applying an approximately 8 times higher $\mathrm{N}_{2}$ pressure, avoiding at the same time the danger of melt boiling. In Table II the compositions of the alloys discussed in this paper are given. The nitrided cylinders with a 50 $\mathrm{mm}$ diameter and a length of $90 \mathrm{~mm}$ were then homogenized for 24 hours at $1250^{\circ} \mathrm{C}$. In order to obtain a fine and homogenous disper-

Table II Chemical composition of tested alloys (wt.\%)

\begin{tabular}{ccccccccc}
\hline $\mathrm{Cr}$ & $\mathrm{Mo}$ & $\mathrm{W}$ & $\mathrm{Ta}$ & $\mathrm{Co}$ & $\mathrm{Al}$ & $\mathrm{V}$ & $\mathrm{N}$ & $\mathrm{P}\left(\mathrm{N}_{2}\right)$ \\
\hline 30 & - & - & - & - & - & - & 0.89 & 20 \\
30 & - & 5 & - & - & - & 0.2 & 0.17 & 10 \\
30 & - & 5 & - & - & - & - & 0.75 & 20 \\
30 & 4 & - & - & - & - & - & 0.7 & 10 \\
30 & 8 & - & - & - & & - & 0.38 & 6 \\
30 & 8 & - & - & - & - & - & 0.67 & 10 \\
25 & - & - & 6 & - & & - & 0.63 & 25 \\
30 & - & - & - & 6 & - & - & 0.58 & 20 \\
25 & - & 5 & 6 & - & 0.5 & - & 0.50 & 15 \\
25 & - & 8 & - & - & 0.5 & - & 0.12 & 10 \\
\hline
\end{tabular}

sion of the nitrides, the specimen were forged in the temperature range $1150-1200^{\circ} \mathrm{C}$ to $15 \times 90 \times$ Ymm blocks, which were then reheated to $1200^{\circ} \mathrm{C}$ before quenching. Since alloys must not be brought to forging temperature too quickly, otherwise microcraks develop and the material loses its workability, the blocks were first preheated in 30 minutes to $700^{\circ} \mathrm{C}$ and then transferred to the oven at $1200^{\circ} \mathrm{C}$.

\section{Ni-Cr-N system}

A peritectoid reaction has been observed by dilatometry in the al- loys Ni30Cr0.9N, Ni30Cr4Mo0.7N, Ni30Cr8Mo0.7N and $\mathrm{Ni} 30 \mathrm{Cr} 5 \mathrm{~W} 0.75 \mathrm{~N}$. Dilatometry was carried out in an argon atmosphere with a constant heating and cooling rate of $0.2^{\circ} \mathrm{C} / \mathrm{s}$, in the 900 to $1300^{\circ} \mathrm{C}$ temperature range, where the reaction was expected.

\section{High temperature properties}

Two alloys were selected for testing the high temperature effect of the nitrides at $1100^{\circ} \mathrm{C}$ : $\mathrm{Ni} 30 \mathrm{Cr} 6 \mathrm{Co} 0.6 \mathrm{~N}$ and $\mathrm{Ni} 30 \mathrm{Cr} 8 \mathrm{Mo} 0.4 \mathrm{~N}$. At this temperature in the former the equilibrium phases are $\mathrm{Cr}_{2} \mathrm{~N}$ and $\gamma$, while in the latter are $\pi$ and $\gamma$. The alloys were aged at $1100^{\circ} \mathrm{C}$ in air for 835 hours.

High temperature tensile tests in air were carried out with a Schenk hydraulic machine at $1000^{\circ} \mathrm{C}$ at a constant rate of $2 \mathrm{~mm} / \mathrm{min}$. A first series of alloys was produced in order to study the effect of nitrogen in solid solution in the Ni30Cr5W alloy. Specimen were tested after $45-60$ stabilization at $1000^{\circ} \mathrm{C} \pm 0.5^{\circ}$. The temperature was monitored directly from a thermocouple placed on the specimen surface. Standard M-10 tensile specimens with a diameter of $6 \mathrm{~mm}$ and a gage length of $30 \mathrm{~mm}$ were used.

\section{Other characterization}

Chemical analysis were conducted with a EDX analyzer, for metallic elements, on a CamScan scanning electron microscope, working at $20 \mathrm{KV}$. Nitrogen content is measured with a LECO TC-436 Nitrogen/Oxygen Determinator, which uses the inert gas fusion principle.

\section{Results and discussion}

\section{Alloys microstructure}

The microstructures of a Ni30 $\mathrm{Cr} 6 \mathrm{Co} 0.6 \mathrm{~N}$ after casting and nitridation, after homogenizing and after forging at $1200^{\circ} \mathrm{C}$ are shown in Figure 3 to Figure 5 respectively. The Co-addition did not affect the nitrogen content obtained after nitriding. The cooling after nitriding is fast enough to avoid the formation of the $\pi$ nitride. $\mathrm{Cr}_{2} \mathrm{~N}$ forms as eutectic lamella during solidification. Homogenizing at $1250^{\circ} \mathrm{C}$ causes the thin nitride lamella to spheroidise, in order to lower interfacial energy. After homogenizing, the nitride particles have a

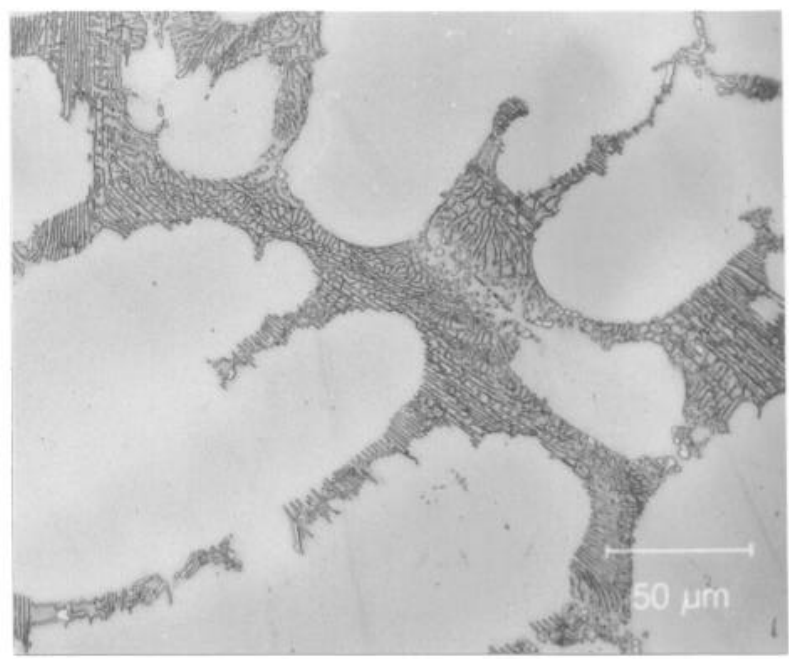

Figure 3: Microstructure of a Ni30Cr6Co0.6N alloy, after nitriding showing the $\mathrm{Cr}_{2} \mathrm{~N}$ lamella. 
size of 1 to $5 \mu \mathrm{m}$.

The hot workability of the alloys, including the alloys containing Mo, W or Ta, is good. The presence of the nitride particles does not affect the workability of the materials for alloys containing less than 20 vol.\%. Specimen containing more than 20 vol. $\%$ showed poor workability (cracking). The microstructure has a grain size

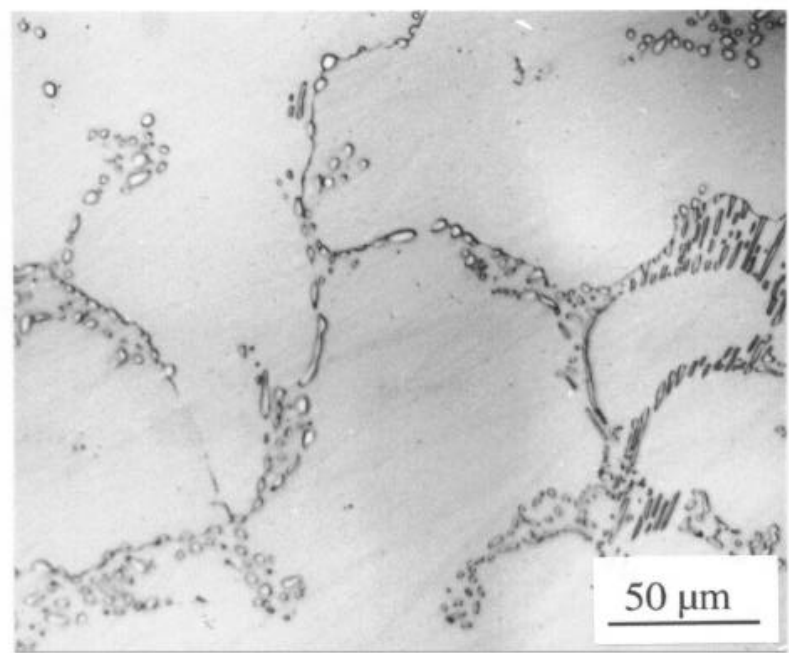

Figure 4: Microstructure of $\mathrm{Ni} 30 \mathrm{Cr} 6 \mathrm{Co} 0.6 \mathrm{~N}$ after 24 hours at $1250^{\circ} \mathrm{C}$.

close to $50 \mu \mathrm{m}$, and a fairly homogeneous distribution of nitride particles. The nitride volume fraction of the specimen shown in (Figure 5) is 0.12 , as determined by quantitative image analysis.

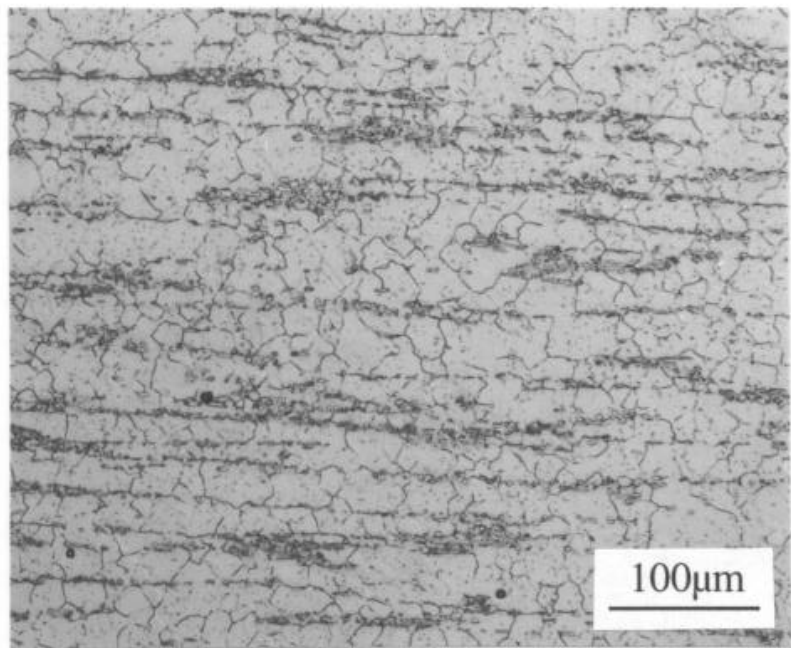

Figure 5: Microstructure of $\mathrm{Ni} 30 \mathrm{Cr} 6 \mathrm{Co} 0.6 \mathrm{~N}$ after forging.

The same manufacturing process was tested on similar alloys alloyed with Ta, Mo and W (Figure 6). The nitriding was successful in all cases, even though variations in the nitrogen content occurred depending on alloy composition. As the alloy in the nitriding furnace was cooled down rapidly, the microstructure was composed in all cases of $\gamma$ and chromium nitride lamella. The lamella contain a non negligible amount of Ta (30wt.\%), in the alloy where this element is present. After aging at $1100^{\circ} \mathrm{C}$ for 835 hours, this alloy developed a microstructure composed of $\gamma$, a Ni-Ta-Cr phase and the
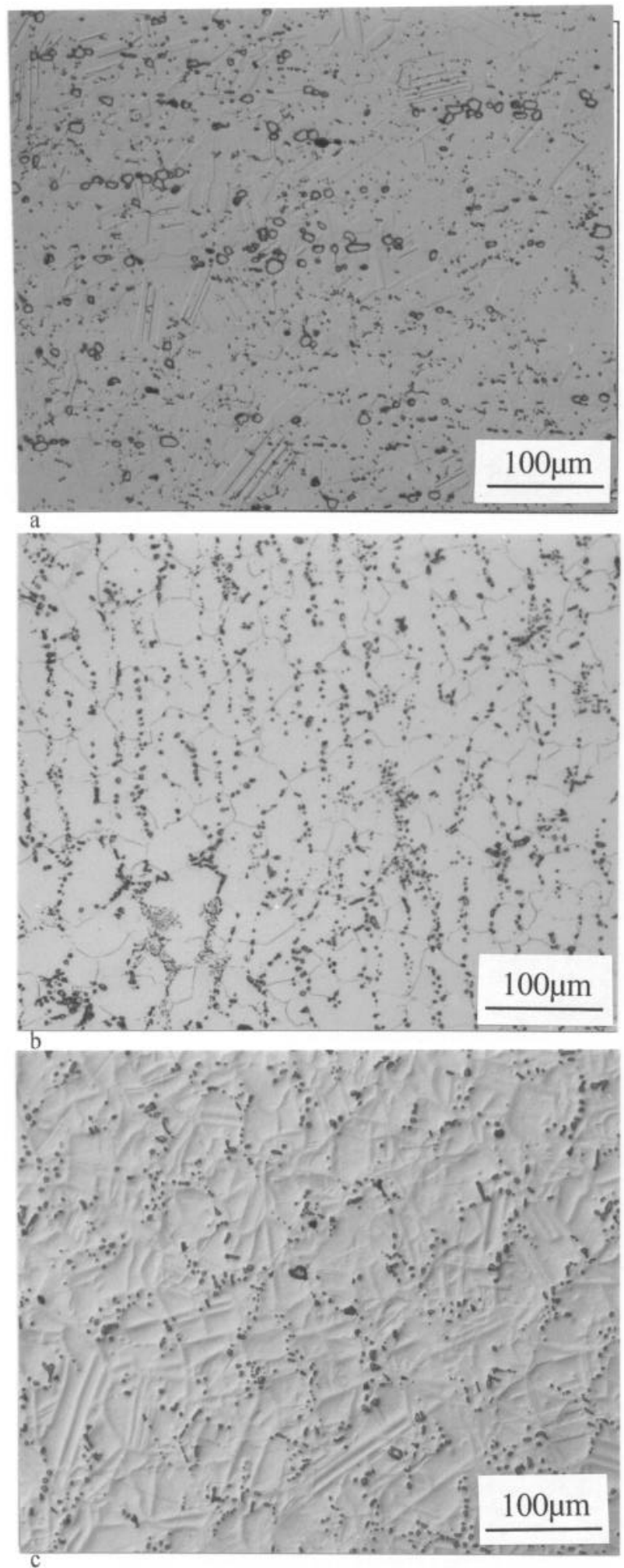

Figure 6: Examples of nitrided, homogenized and forged alloys: (a) $\mathrm{Ni} 30 \mathrm{Cr} 8 \mathrm{Mo0} .6 \mathrm{~N}$, (b) Ni25Cr6Ta0.6N and (c) Ni25Cr4W6Ta0.5N.

$\pi$ nitride, as predicted by the thermodynamical calculations. The Mo-alloyed specimen after homogenization was composed of $\gamma$ and $\pi$, while the W- and Co-alloyed specimen were composed of $\gamma$ and $\mathrm{Cr}_{2} \mathrm{~N}$. In all cases the hot workability was fairly good, and the ni- 
trides were dispersed quite uniformly throughout the volume of the material. Many annealing twins could be observed in the alloys containing tungsten, tantalum and molybdenum additions.

\section{The peritectoid reaction}

The phase transformation between $\mathrm{Cr}_{2} \mathrm{~N}, \gamma$ and $\pi$ phase (see equation 1) revealed a measurable volume decrease in the material of the order of $0.1 \%$. The change was detected by dilatometry, during heating and cooling at a constant rate. It was therefore possible to study this reaction and the effect of alloying W and Mo on the material. Figure 7 shows an example of a dilatometry test run on the alloy $\mathrm{Ni} 30 \mathrm{Cr} 0.9 \mathrm{~N}$. The measured relative change in length of the specimen was converted into relative rate of length change, which would give a peak in the temperature range of the reaction. Of course kinetics effect must be taken into account and the estimated temperatures are slightly shifted to lower temperatures, if measured during heating, and to higher temperatures, if measured during cooling.

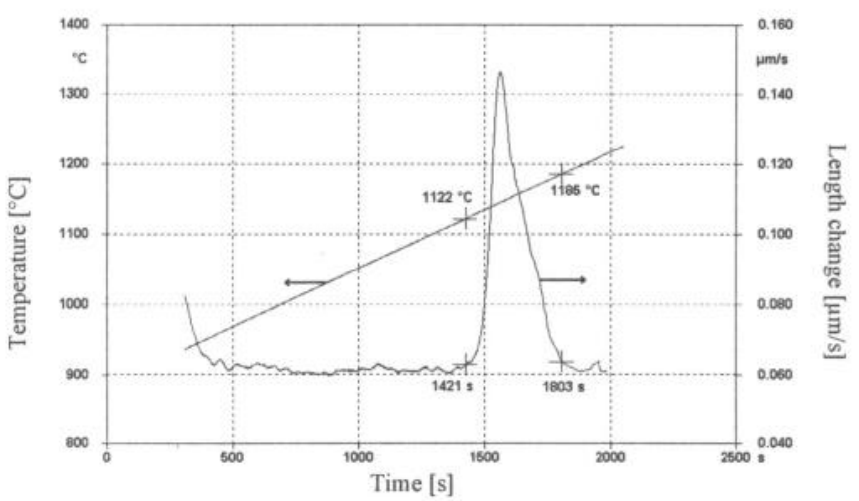

Figure 7: Dilatometry result of test ran on $\mathrm{Ni30Cr} 0.9 \mathrm{~N}$.

The results obtained with different specimens (Table III) show the influence of $\mathrm{W}$ and Mo on the reaction, i.e. relative stability of the nitrides. As it can be seen both $\mathrm{W}$ and Mo cause a shift to higher temperatures; two facts can be responsible. On one side, the presence of atoms with a much larger atomic radius, and a lower mobility, can lower the nitrogen diffusivity, and therefore the ,incubation" time of the reaction. On the other side, W and Mo can substitute for part of the $\mathrm{Cr}$ in the $\pi$ phase, as revealed by EDX, and therefore have a stabilizing effect, shifting the reaction to higher temperatures. The $\pi$ nitride appears to be greatly stabilized by Mo,

Table III Effect of Mo- and W-additions on $\gamma+\mathrm{Cr}_{2} \mathrm{~N} \rightarrow \pi$ reaction temperatures.

\begin{tabular}{|c|c|c|c|c|}
\hline $\mathrm{Ni} 30 \mathrm{Cr}-$ & $0.9 \mathrm{~N}$ & $4 \mathrm{Mo} 0.7 \mathrm{~N}$ & $8 \mathrm{Mo} 0.7 \mathrm{~N}$ & $5 \mathrm{~W} 0.7 \mathrm{~N}$ \\
\hline$\Delta \mathrm{T}$ (up) & $1120^{\circ}-1185^{\circ}$ & $1210^{\circ}-1280^{\circ}$ & $>1300^{\circ}$ & $1160^{\circ}-1180^{\circ}$ \\
\hline$\Delta \mathrm{T}($ down$)$ & $1180^{\circ}-1195^{\circ}$ & $1260^{\circ}-1280^{\circ}$ & $>1300^{\circ}$ & $1180^{\circ}-1240^{\circ}$ \\
\hline $\begin{array}{l}\pi \text { compos. } \\
{[w t . \%]}\end{array}$ & $\begin{array}{l}\mathrm{Ni} 42 \\
\mathrm{Cr} 58\end{array}$ & $\begin{array}{l}\mathrm{Ni} 41 \\
\mathrm{Cr} 51 \\
\mathrm{Mo} 8\end{array}$ & $\begin{array}{l}\text { Ni } 43 \\
\text { Cr } 45 \\
\text { Mo } 11\end{array}$ & $\begin{array}{l}\mathrm{Ni} 41 \\
\mathrm{Cr} 53 \\
\mathrm{~W} 4.5\end{array}$ \\
\hline $\begin{array}{l}\gamma \text { comp. } \\
{[w t . \%]}\end{array}$ & $\begin{array}{l}\mathrm{Ni} 77 \\
\mathrm{Cr} 23\end{array}$ & $\begin{array}{c}\text { Ni } 69 \\
\text { Cr } 28 \\
\text { Mo } 3.5\end{array}$ & $\begin{array}{c}\text { Ni } 65 \\
\text { Cr } 29 \\
\text { Mo } 6.5\end{array}$ & $\begin{array}{l}\text { Ni } 68 \\
\text { Cr } 26 \\
\text { W } 5\end{array}$ \\
\hline
\end{tabular}

as also confirmed in reference 18 to a point that in the specimen containing $8 \mathrm{wt} . \% \mathrm{Mo}, \mathrm{Cr}_{2} \mathrm{~N}$ can only be observed in a fast cooled melt, while after homogenization at $1250^{\circ} \mathrm{C} \pi$ nitrides only are found. The tungsten addition has a similar effect, even though less dramatic. The effects of alloying Mo and W are for both heating and cooling measured reaction temperature ranges very similar. It can be concluded therefore, that Mo and W effectively stabilizes the $\pi$ nitride shifting the reaction to higher temperatures

\section{$\underline{\text { High temperature properties }}$}

In order to monitor the high temperature stability of the microstructure two alloys were aged at $1100^{\circ} \mathrm{C}$, which is the temperature considered as the upper limit service temperature for the present development. The compositions Ni30Cr6Co0.6N and

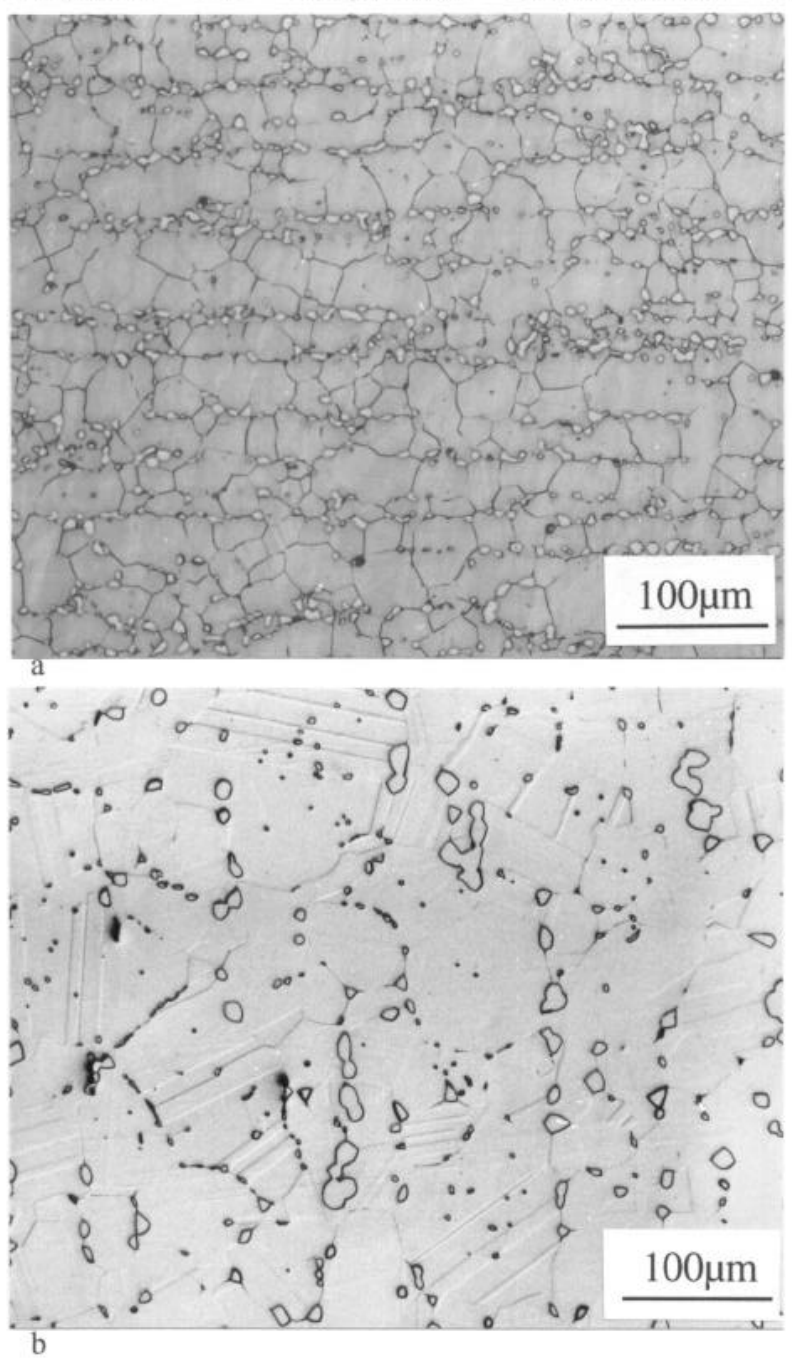

Figure 8: Alloys Ni30Cr6Co0.6N (a) and Ni30Cr8Mo0.7N (b) after 835 hours at $1100^{\circ} \mathrm{C}$.

$\mathrm{Ni} 30 \mathrm{Cr} 8 \mathrm{Mo} 0.4 \mathrm{~N}$ were chosen in order to study the microstructure stability for both $\mathrm{Cr}_{2} \mathrm{~N}$ and $\pi$ nitrides. Figure 8 shows the microstructure of the two alloys after 835 hours aging at $1100^{\circ} \mathrm{C}$ (see for comparison the microstructures after forging in Figure 5 and Figure 6a). As it can be observed, a certain change in the distribution and size of the particles has occurred, while the grain size has increased only very slightly, remaining close to $50-100 \mu \mathrm{m}$. This increase in nitride volume fraction probably takes place during annealing at the 
expense of submicron nitride particle, residues after forging, and of the slightly nitrogen supersaturated $\gamma$. This is also confirmed by the change in hardness measured after annealing in $\gamma$ in the Ni30Cr6Co0. $\mathrm{N}$ alloy dropping from $235 \pm 7 \mathrm{HV}^{0.05}$ to $208 \pm 3$ $\mathrm{HV}^{0.05}$.

\section{Mechanical properties}

Tensile tests at $1000^{\circ} \mathrm{C}$ were run on specimens of composition $\mathrm{Ni}$ $30 \mathrm{Cr}-5 \mathrm{~W}, \mathrm{Ni}-30 \mathrm{Cr}-5 \mathrm{~W}-0.17 \mathrm{~N}$ and Ni-25Cr-8W-0.12N. In both nitrided alloys all the nitrogen is in solid solution; in both cases after annealing at $900^{\circ} \mathrm{C}$ only a minor amount $(<0.5 \mathrm{vol} . \%)$ of nitride precipitation was observed on the grain boundaries.

The results in Figure 9 show remarkable differences in both strength and stress-strain behavior between the nitrogen-free and the nitrided specimens. The strength is basically doubled, and in the nitrided case a pronounced yield point appears (see Figure 9 and Figure 10). Moreover, if the tensile test is unloaded for a few seconds, a new yield point appears, showing a strain aging phenomenon (Figure 10). These tested specimens had a quite large grain size between 300 and $400 \mu \mathrm{m}$. These results clearly indicate a major role played by nitrogen.

The strain aging effect has two possible interpretations. On one side, solid solution strengtheners, on temporarily unloading, are able to diffuse over short distances to dislocation cores anchoring them, resulting in the appearance of a new yield point. The phenomenon is well known: for instance in steels [4] even at $127^{\circ} \mathrm{C}$ interstitial nitrogen and carbon cause strain aging on reloading after

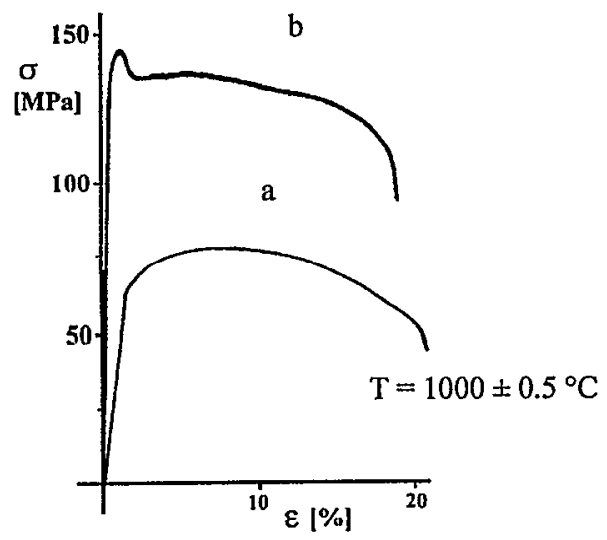

Figure 9: Tensile stress-strain curves for $\mathrm{Ni} 30 \mathrm{Cr} 5 \mathrm{~W} \mathrm{~N}$-free (a) and alloyed with $0.17 \mathrm{wt} . \% \mathrm{~N}(\mathrm{~b})$.

several days. At $1000^{\circ} \mathrm{C}$ even $\mathrm{W}$ atoms may have high enough mobility to participate in the pronounced yield strength, while strain aging, for unloading times of the order of one minute is not likely to be caused by $W$. Therefore the most likely interpretation is that strain aging is caused by nitrogen, which can diffuse rapidly to dislocation cores.

Considering the strong affinity between chromium and nitrogen, clustering or the formation of short range ordering is possible. Then a second possible interpretation is that dislocations are (also) anchored by clusters and under loading once a critical stress is reached brake away or unlocking [21] occurs and a yield point appears. At temperatures high enough, thermal activation allows dislocations to climb and, on unloading, regain an anchored

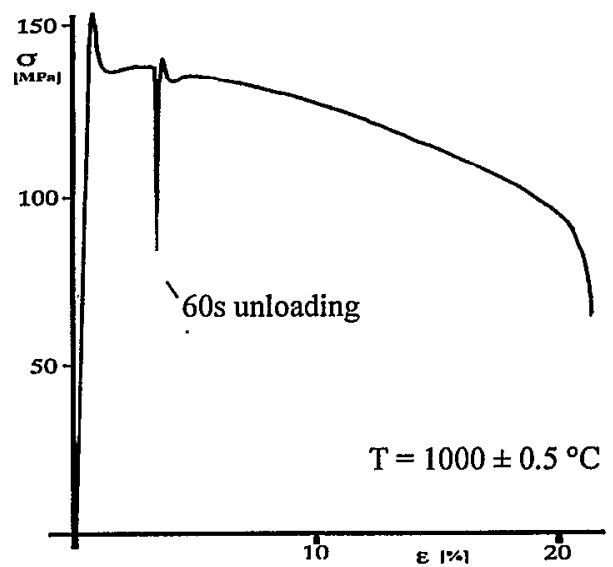

Figure 10: Tensile stress-strain curve for alloy Ni30Cr8W0.12N

placement, which would cause a second yield point. TEM investigations are necessary for confirmation of this point.

On the same alloy, but with a higher nitrogen content ( $0.75 w \mathrm{t} . \%)$, $\mathrm{x}$-ray diffraction phase identification analysis was carried out. The diffraction spectrum, shown in Figure 11, clearly reveals the presence of nickel, $\alpha$-chromium, traces of $\mathrm{Cr}_{2} \mathrm{~N}$ as well as four peaks which can be attributed to the $\pi$ phase $((013),(123),(134)$ and (125) planes) with the $\beta$-manganese structure and a lattice parameter of $0.624 \mathrm{~nm}$. At small diffraction angles a wide peak is detected, which can be related to the presence of clusters in the matrix (as indicated by the arrow in the figure).

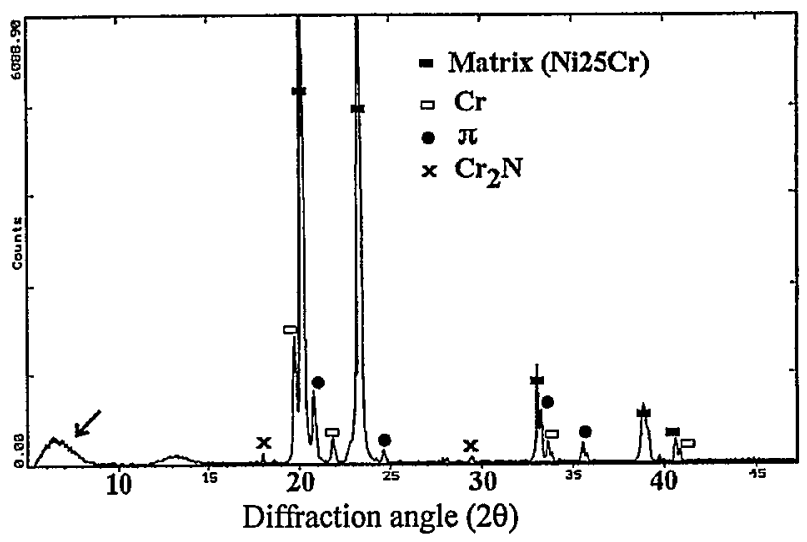

Figure 11: X-ray diffraction spectrum for alloy Ni30Cr5W0.6N (wavelength $0.7092 \AA, \mathrm{Mo}-\mathrm{k}_{\alpha} 2, \mathrm{CT}: 6.5 \mathrm{~s}$ ).

The presence of nitrogen remarkably increases the strength of the material at $1000^{\circ} \mathrm{C}$, while an increase of tungsten, from 5 to $8 \mathrm{wt} . \%$, has a less strong effect; the alloy contains though $0.12 \mathrm{wt} . \% \mathrm{~N}(0.05$ less than Ni30Cr5W). In this case, the first yield point is sharper, confirming that tungsten also contributed to it.

\section{Concluding remarks}

The stability of the microstructure and the good high temperature strength achieved with the combination of $\mathrm{Ni}-\mathrm{Cr}-\mathrm{N}$ with solid solution strengtheners is expected to be the base of a new high temperature alloys family. Strengths above $150 \mathrm{MPa}$ at $1000^{\circ} \mathrm{C}$ should be reached, combining the strengthening effects of nitrogen, substitut- 
ed elements, nitrides and grain boundaries. Creep tests need to be carried out, in order to confirm the inhibition of grain boundary sliding by the presence of nitride particles.

\section{Summary of results}

$\mathrm{Ni-Cr}$-base alloys were nitrided in the liquid phase under high nitrogen partial pressures. For supersaturated alloys, lamellar nitrides are formed during the solidification; these can be broken up and homogeneously disperse in the matrix by means of thermomechanical treatments.

In the $\mathrm{Ni}-\mathrm{Cr}-\mathrm{N}$ system $\mathrm{Cr}_{2} \mathrm{~N}$ as well as the $\pi$ nitride can be formed. The $\pi$ phase become unstable above $1180^{\circ} \mathrm{C}$ but it is strongly stabilized by additions of $\mathrm{Mo}$ and, less dramatically however, by addition of $W$. Under $1180^{\circ} \mathrm{C}$ the $\pi$ phase appears through a peritectoid reaction accompanied by a volume change of the order of $0.1 \%$. With a dispersion of fairly coarse nitrides a grain size close to 50 $\mu \mathrm{m}$ was maintained after 835 hours at $1100^{\circ} \mathrm{C}$.

The strengthening by nitrogen and tungsten allowed to reach tensile strengths above $150 \mathrm{MPa}$ at $1000^{\circ} \mathrm{C}$. Evidence for cluster formation induced by the presence of nitrogen at $1000^{\circ} \mathrm{C}$ was found, and the appearance of a pronounced yield point and strain aging can, at least partially, be related to it.

\section{References}

1. U. Brill and D. C. Agarwal, „Alloy 2100GT: a New Ta-fortified Ni-Cr-Al-Alloy for Land Gas Turbines", Corrosion 99 (NACE, Houston TX, 1999), paper No.57.

2. T. Matsuo, M. Kikuchi and M. Takeyama, „Strengthening Mechanisms of Ni-Cr-W Based Superalloys for Very High Temperature Gas Cooled Reactors" ${ }^{c}$, Proc. First Int. Conf. of Heat-Resistant Materials, (ASM International, Ohio, USA, 1991), 601-614.

3. T. Matsuo et al.,"Strengthening of Nickel-Base Superalloys for Nuclear Heat Exchanger Applications", J. of Material Science 22 (1987), 1901-1907.

4. George D. Dieter, Mechanical Metallurgy (London, McGraw-Hill Book Company, UK, 1988), 203.

5. A. R.Braun and J. F. Radavich, „Microstructural and Mechanical Properties Comparison of P/M 718 and P/M TA 718“" Superalloy 718 - Metallurgy and Applications (Warrendale PA, E.A. Loria, Metals and Materials Society, 1989), 623-629.

6. H. S. Ko, K.W. Paik et al., „Influence of Rhenium on the Microstructures and Mechanical Properties of a Mechanically Alloyed Oxide Dispersion-Strengthened Nickel-Base Superalloy", J. of Mat. Science 33 (13) (1998), 3361-3370.

7. V. G. Gavriljuk and H. Berns, „High Nitrogen Steels, Structure, Properties, Manufacturing, Applications" (Springer-Verlag Berlin, 1999), 10.

8. T. Rosenqvist, Principles of Extractive Metallurgy (London, McGraw Hill Book Company, 1974), 250.

9. X. J. Wu and A. K. Koul, „Grain Boundary Sliding in the Presence of Grain Boundary Precipitates during Transient Creep“", Metall. and Mat. Trans. A 26A (1995), 905-914.

10. F. T. Furillo, J. M. Davidson and J. K. Tien, „, The Effect of
Grain Boundary Carbides on the Creep and Back Stress of a NickelBase Superalloy“, Materials Science and Eng. 39 (1979), 267-273.

11. X. J. Wu and A. K. Koul, ,Modeling Creep in Complex Engineering Alloys", Creep and Stress Relaxation in Miniature Structures and Components, ed. H. D. Merchant (Warrendale PA, The Minerals, Metais \& Materials Society, 1997), 3-17.

12. H. Lüthy, R. A. White and O. D. Sherby, „Grain Boundary Sliding and Deformation Mechanism Maps", Materials Science and Eng. 39 (1979), 211-216.

13. R. Castillo, A. K. Koul and J-P. A. Immarigeon, „The Effect of Service Exposure on the Creep Properties of Cast IN-738LC Subjected to Low Stress High Temperature Creep Conditions", Superalloys 1988 (Warrendale PA, S. Reichman, D.N. Duhl, G. Maurer, S. Antolovich and C. Lund, The Metallurgical Society, 1988), 805-814.

14. H. Suzuki and K. Nakanishi, ,A Theory of the Grain Size Dependence of the Yield Stress in Face-Centered Cubic Alloys", Trans. JIM 16 (1975), 17-27.

15. K.J. Irvine, T. Gladman and F.B. Pichering, ,The Strength of Austenitic Stainless Steels“, JISI 199 (1969), 1017-1028.

16. M. F. Ashby, J. Harper and J. Lewis, "The Interaction of Crystal Boundaries with Second-Phase Particles", Trans. Metallurgical Society of AIME, 245 (1969), 413-420.

17. M. F. Ashby, „The Influencc of Particles on Boundary Mobility", Recrystallization and Grain Growth of Multi-Phase and Particle Containing Materials, Proc. Conf. 1st Int. Symp. on Metallurgy and Materials Science (ed. N. Hansen, A. R. Jones and T. Leffers, Riso National Lab., Roskilde, Denmark, 1980), 325-336.

18. N. Ono, M. Kajihara, and M. Kikuchi, „Formation and Stability of a Nitride with the Structure of Beta Manganese in Ni-CrN Ternary System", Metallurgical Transactions A, 23A (1992), 1389-1393.

19. U. Brill, D. C. Agarwal, „Properties and Corrosion Resistance Behavior of a New Nitride-Strengthened Nickel-Chromium Superalloy" , Corrosion 98 (NACE, Houston TX, 1998), paper No.437.

20. Y. Zhang, D. Zhu and D. A. Shores, „Effect of Yttrium on the Oxidation behavior of Cast Ni-30Cr Alloy", Acta metall. mater., 43 (1995), 4015-4025.

21. R. W. Balluffi and A. V. Granato, ,Dislocations, Vacancies and Interstitials", Dislocations in Solids, ed. F. R. N. Nabarro (Oxford, North-Holland Publishing Company, 1983), 32-35. 